\title{
Awareness and Attraction or Adhesion and Activation
}

\section{Rüdiger E. Scharf}

Division of Experimental and Clinical Hemostasis, Hemotherapy and Transfusion Medicine, and Hemophilia Comprehensive Care Center, Institute of Transplantation Diagnostics and Cell Therapy, Heinrich Heine University Medical Center, Düsseldorf, Germany
A new year has begun, and challenges remain. For example, the Editor and the Editorial Board Members are constantly scouting for innovations to increase the awareness of Hämostaseologie - Progress in Haemostasis among physician-scientists and health professionals, specifically to enhance the attraction of the Journal to our readers.

A straightforward action would be to make the Journal more informative. However, that is easier said than done, particularly in the era of rapid communication and easy online access to scientific papers. What exactly do we wish to achieve? Translated into biological terms, the overall idea and elements of a core concept are: (i) to make our readers 'adherent' onto Hämostaseologie - Progress in Haemostasis, (ii) to induce 'activation', whenever appropriate, and (iii) to promote 'interactions.' These sequential steps require a 'fertile environment' and a specific 'feel' or a 'sense of home' that our readers can associate with the Journal.

\section{Novel categories of the Journal}

It remains true that new discoveries in hemostasis and thrombosis, such as molecular or mechanistic insights into biological or pathological processes, and novel treatment modalities in our field are not primarily published in Hämostaseologie -

Correspondence to:

Univ.-Prof. Dr. Rüdiger E. Scharf, F.A.H.A.

E-mail: rscharf@uni-duesseldorf.de

Hämostaseologie 2018; 38: 5-6

received and accepted: January 22, 2018
Progress in Haemostasis. But the Journal can help to communicate, distribute and reinforce relevant information on pioneering ideas and groundbreaking accomplishments among GTH members and affiliated scientists. To do so, in 2016, a new category on "hot topics" was introduced in the Journal, entitled "Reviewed \& Commented".

Our readers were invited to submit brief articles, commenting on topics of interest and late-breaking news published in highranked scientific journals (1). Since then, two contributions appeared $(2,3)$, both of which commented on clinical studies published in The New England Journal of Medicine, reporting on advances in hemophilia care using non-factor replacement therapies (4-6). Physician-scientists should feel encouraged to submit reviews and comments on recent publications in other journals.

Another format that was introduced by Johanna Kremer Hovinga at the GTH Congress 2017 and subsequently implemented in Hämostaseologie - Progress in Haemostasis are Highlight presentations. These contributions cover brief personal statements on novel and/or controversial topics in our field. A series of highlight articles was published in issue 3/2017 and had a focus on novel treatment options in TTP (7), hemophilia A (8), or myocardial infarction in a neonate (9). The highlight category will be continued in 2018, and GTH members are invited to submit corresponding manuscripts.

Scientific news can also be presented in a condensed format and may have sustained effects to readers when combined with visual information (10). In the light of this perception, a new format entitled Images in Thrombosis \& Haemostasis was launched in 2017. The idea of images in $T \& H$ originated from Bernhard Lämmle,

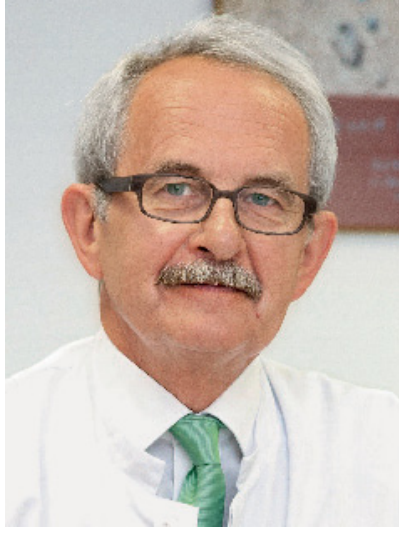

Prof. Dr. Rüdiger E. Scharf Division of Experimental and Clinical Hemostasis, Hemotherapy and Transfusion Medicine, and Hemophilia

Comprehensive Care Center, Institute of Transplantation Diagnostics and Cell Therapy, Heinrich Heine University Medical Center, Düsseldorf, Germany 
who together with his associates in Mainz contributed the inaugural article (11).

In this issue of Hämostaseologie - Progress in Haemostasis, the series of images in $T \& H$ is being continued. Signe Østergård et al. report on ovarian vein thrombosis, thereby presenting CT scans (12). Again, our readers are encouraged to submit short manuscripts and exploratory or educational illustrations that fit into the images in T\&H category.

\section{Achievements \& acknowledgements}

2017 has been a successful year for the Journal. As communicated by mid-June, the impact factor for 2016 has increased to 1.828 (10). The number of submissions reporting on original work has increased by $20 \%$ with a parallel progression in the rate of manuscripts that need to be rejected. Currently, the Journal's accept ratio is at $58 \%$. Upon peer-review by expert referees and a Section Editor, every other manuscript has to undergo major revision. Submissions by invited authors are no exception to this. But it is worth making the effort.

As Editor, I am grateful to the authors, the Editorial Board Members and the referees for their work and input, and, last but not least, to our loyal readership. With this editorial, I am extending best wishes to our readers for the New Year. We thank you for your interest, your trust and your suggestions - stay with us.

\section{References}

1. Scharf RE. Hamostaseologie - Progress in Haemostasis. Recent achievements and future directions. Hämostaseologie 2016; 36: 157-158.

2. Scharf RE. Hot topic: Alloantibodies to therapeutic FVIII and the use of emicizumab in hemophilia A. Hämostaseologie 2016; 36: 195-198.

3. Tiede A. Thrombotic risks of non-factor replacement therapies in hemophilia. Hämostaseologie 2017; 37: 307-310.
4. Shima M, Hanabusa H, Taki M, et al. Factor VIIImimetic function of humanized bispecific antibody in hemophilia A. N Engl J Med 2016; 374: 2044-2053.

5. Oldenburg J, Mahlangu JN, Kim B, et al. Emicizumab prophylaxis in hemophilia A with inhibitors. N Engl J Med 2017; 377: 809-818.

6. Pasi KJ, Rangarajan S, Georgiev P, et al. Targeting of antithrombin in hemophilia A or B with RNAi therapy. N Engl J Med 2017; 377: 819-828.

7. Knobl P. New treatment options for thrombotic thrombocytopenic purpura. Hämostaseologie 2017; 37: 211-215.

8. Klamroth R. A new era of treatment for patients with haemophilia A? Hämostaseologie 2017; 37: 216-218.

9. Streif W. Myocardial infarction in a neonate. Lessons for neonatal and internal medicine. Hämostaseologie 2017; 37: 219-222.

10. Scharf RE. Pictures tell their own story. Images in Thrombosis and Haemostasis. Hämostaseologie 2017; 37: 181-183.

11. Trinchero A, Schotten S, Lammle B, Pitton MB. May-Thurner syndrome: missed diagnosis and missed early treatment? Hämostaseologie 2017; 37: 184-185.

12. Ostergaard S, Hvas AM, Medrud L, Fuglsang J. Ovarian vein thrombosis after delivery. Hämostaseologie 2108; 38: 9-10.

\section{Central Editorial Office \\ Farewell and Welcome}

As of January 31, Dr. Peter Henning left the Editorial Office of Hämostaseologie - Progress in Haemostasis to assume responsibility of several other Schattauer journals at Thieme. On behalf of the Editorial Board Members, I wish to express our gratitude and recognition for his activity and support. As Editor, I really appreciated Dr. Henning's professional service, including his effective troubleshooting, whenever required.

Since February 1, Dr. Elinor Switzer has been managing the Journal's Central Editorial Office.
By her longstanding work with Thrombosis \& Haemostasis, Dr. Switzer is well known to the scientific community. We are very pleased about her appointment and are looking forward to working with her. Moreover, Dr. Anja Borchers will coordinate the reports of partners from research and industry and manage the Journal's 'blue pages'. Welcome on bord!

Rüdiger E. Scharf, Editor-in-Chief 